\title{
Disease of the small bowel in childhood
}

\author{
J. A. WALKer-SMith* \\ M.B., M.R.C.P.E., M.R.C.P., M.R.A.C.P. \\ Department of Child Health, University of Sydney and Royal Alexandra Hospital for Children, \\ Camperdown, Sydney, N.S.W., Australia
}

\section{Introduction}

The small intestine is the principal organ of absorption in the body, thus complete resection is not compatible with life (Doolan et al., 1951). However extensive small bowel resections are, for a time at least, compatible with survival (McMahon, 1966; Walker-Smith \& Wyndham, 1967a), but cause a profound disturbance of digestion and absorption. The three main functions of the small bowel are: (1) the onward passage of the ingested food bolus, (2) continued digestion of this bolus, (3) absorption of the digested nutrients into the blood and lymph vessels. Thus, disease of this organ may manifest as a disruption of one or all three of these functions. Interference with the first produces the syndrome of intestinal obstruction and disorders of the second and third usually produce diarrhoea and malabsorption.

In childhood, intestinal obstruction due to congenital abnormalities of the small bowel usually presents acutely and requires urgent surgical treatment, whilst disorders of digestion and absorption may be more insidious in onset and occult in their clinical manifestations. Indeed, although disorders of digestion and absorption usually manifest with diarrhoea and malabsorption, significant disease of the small bowel may be present in children, as biopsy studies have shown, in the absence both of diarrhoea and of evidence of malabsorption by the usual clinical screening tests. If such abnormalities remain unrecognized, they may gravely interfere with growth and development.

The introduction of safe methods to biopsy the small bowel mucosa in childhood (Sakula \& Shiner, 1957; Crosby \& Kugler, 1957; Cameron et al., 1962) has enabled knowledge of disease of this organ to be considerably extended in the paediatric age-group. Nevertheless, much remains unknown, and although a single biopsy may reveal proximal small bowel

\footnotetext{
* Wellcome Clinical Research Fellow.
}

abnormality, this gives no indication as to the extent of the abnormality along the gut.

The purpose of this paper is to review several aspects of some predominantly medical diseases of the small bowel which may occur in childhood. The selection of conditions discussed reflects experience at the Royal Alexandra Hospital for Children, Sydney, Australia.

\section{Coeliac disease \\ Definition}

Coeliac disease is a disease of the small intestine, chiefly affecting its proximal portion, occurring in children. It is characterized by an abnormal small intestinal mucosa and associated with a permanent intolerance to gluten. Removal of gluten from the diet leads to clinical and pathological remission.

\section{Incidence}

The incidence of this disease in England has been estimated to lie between 1 in 2000 and 1 in 6000 in a study which did not use small-bowel biopsy in diagnosis (Carter, Sheldon \& Walker 1959). This figure is, therefore probably an under-estimate. At the Royal Alexandra Hospital for Children in the 3 year period 1966-68 there have been 87 new cases of fibrocystic disease of the pancreas and 44 biopsyproven cases of coeliac disease, i.e. a ratio of approximately 2-1. The frequency of fibrocystic disease in an Australian study has been shown to be 1 in 2448 (Danks, Allan \& Anderson, 1965). Thus it is likely that the incidence of coeliac disease producing clinical illness severe enough to warrant hospital admission, in Sydney, is of the order of 1 in 5000. The true incidence is likely to be higher, as cases may be subclinical. This was shown in the survey of MacDonald, Dobbins \& Rubin (1965) who found the characteristic mucosal lesion on biopsy of five asymptomatic siblings of coeliac children. This and other studies have also clearly established the 
familial incidence of the disease, although Hamilton, Lynch \& Reilly (1969) did not find such an incidence. However, McConnell (1966) states that the frequency of this disease in families of coeliac patients is so high that no control series or statistical analysis is necessary to demonstrate the existence of such familial concentration. In a series of fifty-three children with coeliac disease, seen at the Royal Alexandra Hospital for Children, a familial incidence has been found on two occasions. On each occasion, diagnosis in one child led to investigations and diagnosis in a sibling with symptoms. In this series, 28 children were female, 25 male. This is in keeping with the findings of Davidson \& Fountain (1950) who, in the pre-biopsy era, found an equal sex distribution in 1077 cases, although the earlier literature suggested a higher female incidence (Hutchison, 1925).

\section{Genetics}

It has been suggested that coeliac disease is inherited as an incomplete dominant, but the report of a discordant pair of identical twins in adult coeliac disease (Hoffman, Wollaeger \& Greenberg, 1966) is in conflict with this view. The suggestion of McConnell (1966) that the liability to respond to an environmental stress in coeliac disease may be inherited on a polygenic basis seems at present to fit the facts best. The involvement of ABO blood groups in this inheritance has been suggested by the observation that 20 out of 28 cases of adult coeliac disease were blood group O (Joske \& Benson, 1958), but in a subsequent series of 46 adult patients $50 \%$ had blood group A and only $43.5 \%$ group $\mathrm{O}$ (Cooke et al., 1963). No similar series has so far been reported in childhood coeliac disease, but in 28 children studied at the Royal Alexandra Hospital for Children blood group A also occurred in $50 \%$ (Table 1 ).

\begin{tabular}{lr} 
TABLE 1. ABO blood groups in twenty- \\
eight coeliac children seen at the Royal \\
\multicolumn{2}{c}{ Alexandra Hospital for Children } \\
\hline Blood Group A & 14 \\
Blood Group O & 10 \\
Blood Group AB & 2 \\
Blood Group B & 2 \\
\hline
\end{tabular}

\section{Pathogenesis}

The harmful effect of the gluten fraction of wheat and the close relationship between the use of wheat and the degree of steatorrhoea in coeliac disease was established by Dicke in 1950 . The deleterious agent in gluten appears to reside within an acidic peptide fraction (Bronstein, Haeffner \& Knowlessar, 1966) within a molecular weight range of 5000 to 10,000 (Frazer, 1968), but the mechanism of action of this deleterious agent remains uncertain.

A direct 'toxic' effect of gluten upon the intestinal mucosa associated with a specific enzyme deficiency has been postulated, but no such irreversible and permanent enzyme deficiency has yet been demonstrated (Douglas \& Booth, 1968; Gelfand, Spiro \& Herskovic, 1968).

An immunological abnormality with some form of antigen-antibody reaction damaging the intestinal mucosa has also been suggested. However, the available evidence to support this contention is not conclusive.

Although circulating antibodies to wheat fractions and also other dietary proteins have been found in coeliac patients (Taylor et al., 1961; Heiner et al., 1962), using a coated tanned red cell technique, gluten antibodies were not found in all such patients. In twenty-four untreated coeliac children using a micro-Ouchterlony double immunodiffusion test system (Kenrick \& Walker-Smith, 1969), only six children were found to have gliadin antibodies. Three of these were studied again after a gluten-free diet and gliadin antibodies were no longer demonstrable. The demonstration of such antibodies appears to be a secondary phenomenon. Abnormalities of serum immunoglobulins (Immonen, 1967; Hobbs \& Hepner, 1968; Kenrick \& Walker-Smith, 1970) have also been observed in coeliac disease, but here again the available evidence suggests these are reversible and the immunoglobulins return to normal when the child is having a gluten-free diet.

Whatever the genesis of the harmful effect of gluten may be, there appears to be no natural recovery in untreated coeliac patients. It appears that the intolerance to gluten is permanent, although clinical manifestations of this may vary widely. Mortimer et al. (1968) have demonstrated a persistently abnormal mucosa in untreated patients $18-38$ years after the onset of symptoms in childhood. Although Anderson (1960) has shown that these mucosal abnormalities improve on a gluten-free diet and may return to normal, Shmerling (1968a) demonstrated that ten treated coeliac children all developed a flat mucosa when gluten was reintroduced into their diet. However, four out of the ten children developed no clinical or biochemical manifestations of a relapse despite progressive deterioration of their intestinal mucosa. Cameron et al. (1962), Hubble (1963) and Sheldon \& Tempany (1966) have also observed this lack of parallel between mucosal deterioration and clinical relapse. Further long-term follow-up studies of children into adult life, who have developed a flat mucosa once again, after gluten reintroduction into their diet, may, however, reveal a delayed clinical relapse.

\section{Pathology}

Knowledge of the pathology of this condition has chiefly come from small-bowel biopsy studies. These 
have shown that the mucosa of the proximal small bowel is principally affected, both in children and adults (Rubin et al., 1960a; Stewart et al., 1967). This observation accords with the concept of a noxious agent in the diet (viz. gluten) damaging the gut mucosa. Hydrolysed gluten is harmless (Weijers \& Van de Kamer, 1960). It is postulated that by the time any ingested gluten, which is not absorbed proximally, reaches the ileum, it has been completely hydrolysed and so is no longer damaging to the bowel mucosa. However, although usually histologically normal, this distal small-bowel mucosa, in coeliac disease, has been shown by Rubin et al. (1960b), unlike normal mucosa, to react to the direct instillation of gluten with mucosal damage.

Characteristically the proximal small-bowel mucosa in coeliac disease is flat, representing a considerable reduction in absorptive surface area. When a mucosal biopsy is taken, and examined under the dissecting microscope, this may be completely flat and featureless or it may have a flat mosaic appearance with irregular areas divided by grooves (Booth et al., 1962; Walker-Smith, 1967b). In these areas the openings of crypts may be seen. This flat mucosa histologically has an appearance usually known as subtotal villous atrophy (Shiner, 1960), but sometimes as total villous atrophy (Gerrard \& Lubos, 1967). These are unsatisfactory terms as the mucosa is not truly atrophic; indeed the crypts of Lieberkühn are lengthened. There is also a variable cellular infiltration of the lamina propria with round cells. The surface epithelium is low columnar or cuboidal. Booth (1968) has suggested, using an haematological analogy, that the surface epithelial cells lining the intestinal mucosa be called enterocytes and the cells in the crypts of Leiberkühn enteroblasts. He thus describes the surface epithelial cells in coeliac disease as being microcytic enterocytes. At the same time there is thickening of the enteroblastic layer (enteroblastic hyperplasia) with increased mitotic activity in order to replace the enterocytes destroyed and damaged by gluten.

Some children reported to have coeliac disease have a proximal mucosa which is characterized, under the dissecting microscope, by short thickened ridges, sometimes with a convoluted appearance and partial villous atrophy histologically (Sheldon \& Tempany, 1966; McNicholl \& Egan, 1968). This appearance is much less common than a flat mucosa and may occur in a variety of disorders of the small bowel other than coeliac disease.

However, the severity of the biopsy findings is of less importance than the length of small bowel affected (Rubin et al., 1960a), which probably determines the clinical state. The degree of ileal involvement may be crucial in this regard (Stewart et al., 1967).

\section{Clinical features}

There is considerable variation in the age of onset of symptoms in coeliac disease. There is usually a variable 'latent interval' between the introduction of gluten into the diet and the development of clinical manifestations. In twenty-five children seen at the Royal Alexandra Hospital for Children, who had an accurate record kept of the age of gluten introduction, this latent interval varied from a few weeks to $5 \frac{1}{2}$ years (Fig. 1). The explanation for this variable

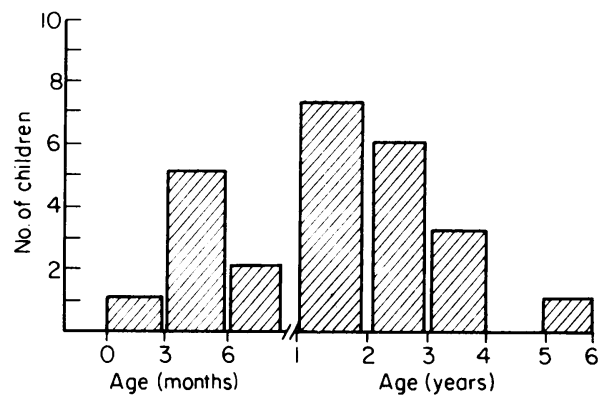

Fig. 1. Latent interval between introduction of gluten to diet and development of symptoms in twenty-five coeliac children at the Royal Alexandra Hospital for Children.

interval is unknown. Some children do develop symptoms as soon as gluten is introduced into their diet and the present trend to early introduction of cereals into an infant's diet means that coeliac disease must be considered in the differential diagnosis of diarrhoea and failure to thrive even in very young infants. The commonest age for the onset of symptoms was in the second year of life in a group of fifty-three children (Fig. 2). A similar age of

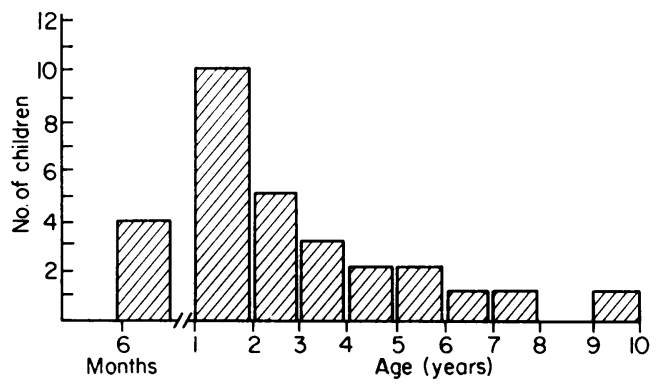

Fig. 2. Age of onset of symptoms in fifty-three coeliac children at the Royal Alexandra Hospital for Children.

presentation has been described by Pringle et al. (1968), but others have observed a more frequent earlier onset in the second six months of life (Shmerling, 1965; Hamilton et al., 1969). The mode of presentation of coeliac disease may be very 
TABLE 2. Mode of presentation of coeliac disease in fifty-three coeliac children at the Royal Alexandra Hospital for Children

\begin{tabular}{lr}
\hline Diarrhoea & 33 \\
Failure to thrive of inapparent cause & 7 \\
Vomiting & 6 \\
Weight loss & 3 \\
Anorexia & 2 \\
Short stature & 1 \\
Protuberant abdomen & 1 \\
\hline
\end{tabular}

variable (Table 2). Diarrhoea, which may be acute or insidious in onset, is the commonest presenting symptom, but failure to thrive of inapparent cause may be its only manifestation. Other modes of presentation include vomiting, weight loss, anorexia, shortness of stature of inapparent cause and hypoproteinaemia with ankle oedema. However, not only may there be no diarrhoea in coeliac children, but early in the illness constipation may occasionally occur. A protuberant abdomen with wasting of the proximal muscles of the limb girdles is often found, but there may be remarkably little to observe on physical examination, apart from measurement of height and weight which are usually below the 10th percentile. Nevertheless, single measurements may be in the normal range, isolated observations may be unreliable and knowledge of earlier measurements is essential for adequate interpretation.

On investigation, there may be evidence of multiple deficiencies in absorption, e.g. steatorrhoea, hypoprothrombinaemia, iron and folic acid deficiency anaemia, a flat oral glucose tolerance test and abnormal xylose absorption. There may, however, be no evidence of such deficiencies. Three-day fat-balance studies in twenty-five coeliac children on a ward diet at the Royal Alexandra Hospital for Children only demonstrated a faecal fat level greater than $4 \mathrm{~g} /$ day in 15 . A similar absence of steatorrhoea in coeliac children has been reported by McNicholl \& Egan (1968) and this was attributed to the length of bowel involved. The paucity of reported studies of fat balances in normal toddlers and infants makes the diagnosis of steatorrhoea difficult in the younger age-groups and the 'normal' figure of $4 \mathrm{~g}$ /day is probably too high in these children.

Coeliac disease has occasionally been observed to occur in diabetic children, but whether there is more than a chance association between the two diseases remains uncertain (Hooft et al., 1968; Walker-Smith \& Grigor, 1969b). Rectal prolapse was observed in in three out of forty-two coeliac children by Hamilton et al. (1969). At the Royal Alexandra Hospital for Children this was found in two our of fifty-three coeliac children.

\section{Diagnosis}

The only satisfactory way to diagnose coeliac disease is by small-bowel biopsy to demonstrate an abnormal mucosa (usually flat) followed by a clinical response to a gluten-free diet. Some observers feel that reintroduction of gluten into the child's diet at a later date when the mucosa has returned towards normal and the subsequent demonstration of clinical and mucosal deterioration, is essential for accurate diagnosis (Frazer, 1968). Such a procedure is not yet standard clinical practice. McNeish (1968a) has shown the importance of reintroducing gluten into the diet of children, in whom there was some doubt about the original diagnosis of coeliac disease, followed after a few weeks by small-bowel biopsy.

Although a flat small intestinal mucosa is no longer considered pathognomonic of coeliac disease it was found in all except two of fifty-three children. A flat biopsy has been seen at the Royal Alexandra Hospital for Children on only one other occasion. This child had a small intestinal lymphangioma at autopsy, but may in addition have had gluten intolerance (Walker-Smith et al., 1969c). A flat mucosa has also been described in tropical sprue (Swanson \& Thomassen, 1965), in kwashiorkor (Stanfield, Hutt \& Tunnicliffe, 1965) and after severe gastroenteritis (Burke, Kerry \& Anderson, 1965).

A convoluted mucosa with partial villous atrophy histologically can occur in coeliac disease, but this appearance can result from many causes and is not typical of coeliac disease.

Attempts to find a clinical test which would indicate the extent of small-bowel mucosal involvement so far have proved unreliable. Xylose absorption is unsatisfactory in this regard. The degree of disacchariduria which may occur in coeliac disease has been considered likely to be an index of the severity and extent of the mucosal damage (Prader, Shmerling \& Hadorn, 1966), but attempts to devise a clinical test based on this hypothesis, using the inert disaccharide lactulose, have proved unsuccessful (Müller et al., 1969).

\section{Treatment}

The elimination of gluten from the diet usually leads to a dramatic and rapid clinical response, but this may sometimes be delayed. Co-existent sugar malabsorption may be responsible for this. Secondary disaccharidase deficiency has clearly been demonstrated in coeliac disease (Shmerling et al., 1964), but in only a few infants is this of clinical significance (McNeish \& Sweet, 1968b). Only when there is such evidence (stool testing, diarrhoea after a lactose load, abnormal barium-lactose meal etc.) is elimination of lactose from the diet indicated.

A gluten-free diet should be continued at least till growth ceases in order to achieve full growth 
potential. Shmerling, Prader \& Zachmann (1968b) have shown that with adequate dietary treatment from about the age of 1 year, coeliac children fully recover from their growth retardation. Children who have had inadequate gluten restriction and have had clinical relapses do not do so well. The demonstration of an increased incidence of malignant disease in adult coeliac disease (Harris et al., 1967) and the suggestion as yet unproved, that a gluten-free diet may reduce this risk, suggests that a gluten-free diet should be continued for life.

\section{Transient gluten intolerance}

A transient or acquired gluten intolerance has been described in adults by Frazer (1968) and in children by Visakorpi \& Immonen (1967). These reports were based on clinical and biochemical response and lacked serial biopsy studies. Nonetheless, there does appear to be a group of children with malabsorption, who appear to respond clinically to a gluten-free diet, but do not relapse on reintroduction of gluten into their diet. Further biopsy studies are necessary to elucidate the nature of this syndrome.

\section{Gastroenteritis}

In clinical practice acute diarrhoeal disease which is often accompanied by vomiting and appears to be infective in origin, during infancy and childhood, is usually referred to as gastroenteritis, but it is also known as infantile diarrhoea or infectious diarrhoea. There is often constitutional disturbance, fever and varying degrees of dehydration. This syndrome must be distinguished from diarrhoea and vomiting which may accompany urinary tract infection, pneumonia, septicaemia and meningitis.

\section{Pathology}

The small bowel is generally the organ principally affected, but the stomach and colon may also be involved. The pathological findings are usually regarded as being non-specific and inconstant. Giles, Sangster \& Smith (1949) described the pathological features, at autopsy, in fifty-five fatal cases in a childhood epidemic of gastroenteritis. There was a mild hyperaemia of the small intestine in twentyeight, submucosal haemorrhages in thirteen and ulceration in four; the small bowel was normal in four children. Ulceration of the small bowel in gastroenteritis appears to be uncommon, but four such cases were described by Dexter \& Gowing in 1954.

The mucosal appearances of the entire length of small bowel at post-mortem can be studied by allowing the surface epithelium to slough off and the connective tissue 'cores' of the villi to be exposed and stained and then examined under the dissecting microscope (Walker-Smith, 1969a). Using this method of examination in seven children who died following the clinical syndrome of gastroenteritis at the Royal Alexandra Hospital for Children an abnormal appearance was observed in all. The villi of the proximal small bowel were replaced by short thick ridges (Fig. 3) extending for various distances

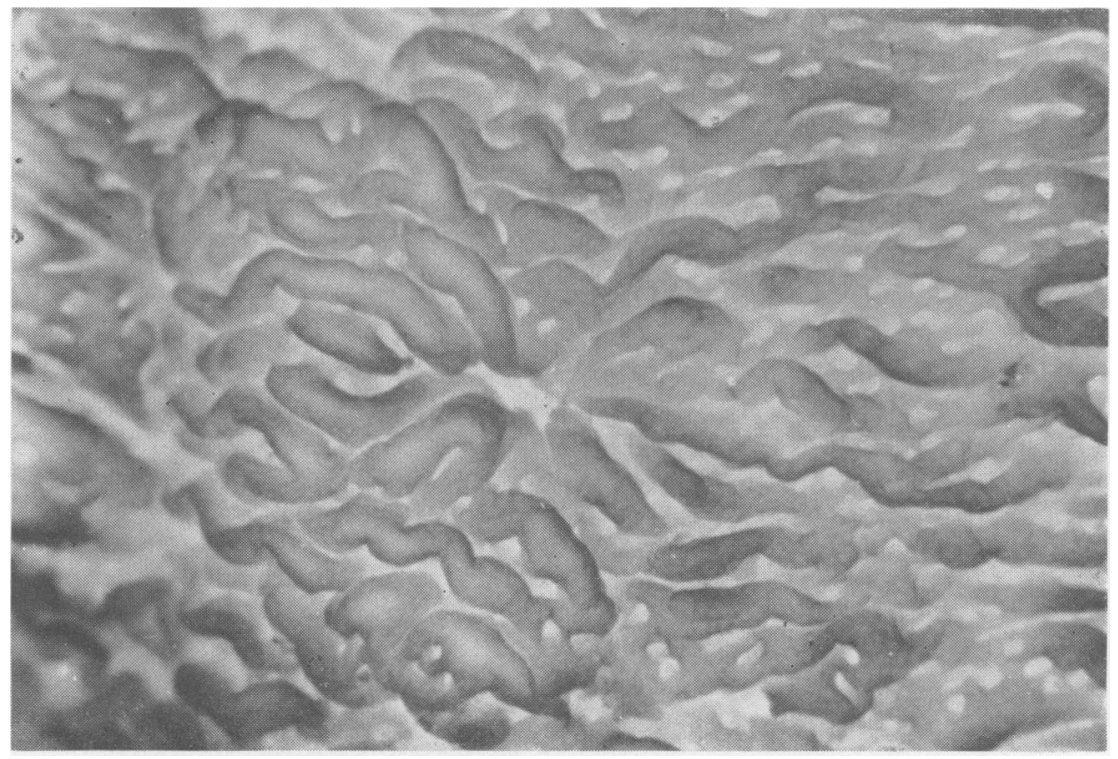

Fig. 3. Dissecting microscope appearance of proximal jejunum, at necropsy, showing short thick ridges and a small ulcer in a child who died following gastroenteritis. 
along the length of the small bowel. In one child the whole length of the small bowel was affected. In two there was ulceration along the small bowel, but chiefly affecting the terminal ileum. These ulcers, histologically, were chronic inflammatory in character with continuing activity and no evidence of regeneration.

Small-bowel biopsy from children who fail to thrive after gastroenteritis often demonstrates the presence of severe partial villous atrophy histologically (Fig. 4a). This may persist for several months (Fig. 4b), but the mucosa usually returns to normal (Fig. 4c).

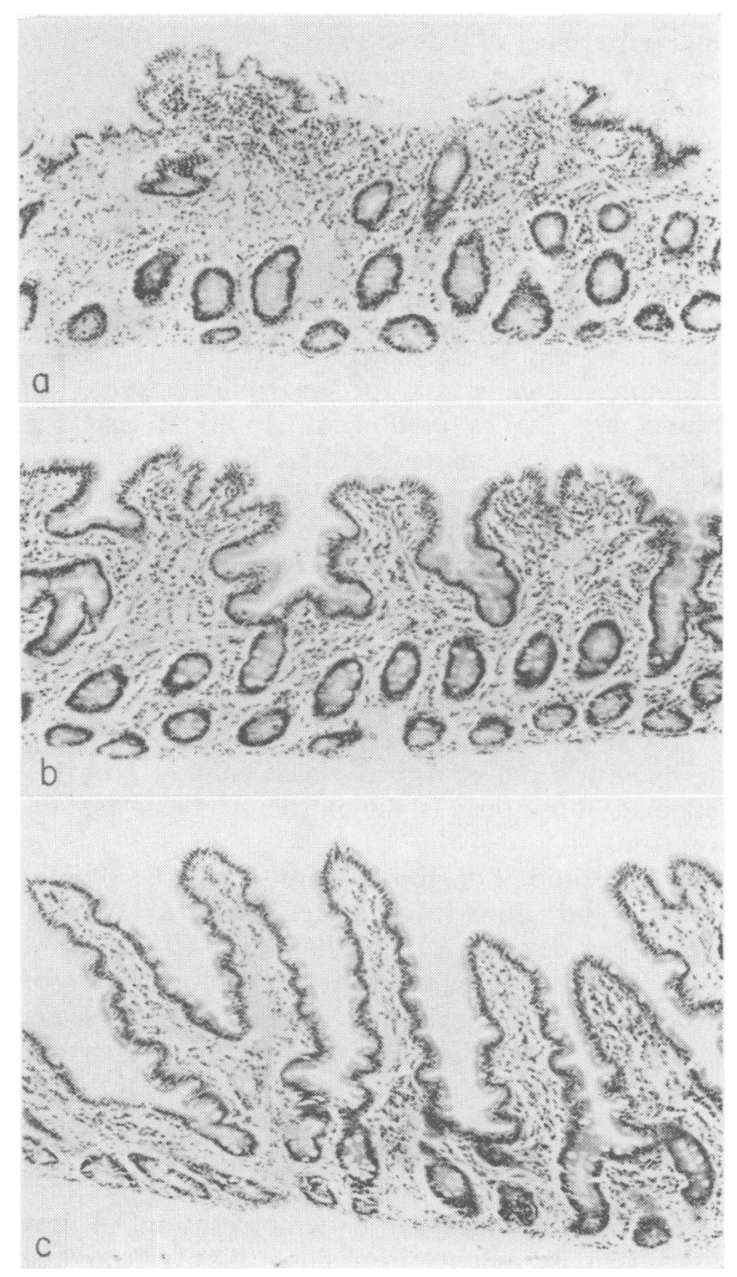

FIG. 4a. Small-bowel biopsy from a 1 year-old child 4 weeks after gastroenteritis showing partial villous atrophy.

FIG. 4b. Persistent partial villous atrophy 10 weeks later.

FIG. 4c. Normal small-bowel mucosa 1 year 2 months after episode of gastroenteritis.

\section{Bacteriology and virology}

The isolation rate of bacterial pathogens from children with acute gastroenteritis is often no higher than $30 \%$ (Table 3) (Dorman, 1969). In some com-

TABLE 3. Incidence of gastroenteritis at the Royal Alexandra Hospital for Children from 1 July, 1967-30 June, 1968

\begin{tabular}{ll}
\hline Total Number of Cases & 828 \\
Salmonellae & $98(12 \%)$ \\
Shigellae & $50(6 \%)$ \\
Enteropathogenic E. coli & $62(7 \cdot 5 \%)$ \\
\hline
\end{tabular}

munities the figure may be as low as $5 \%$ and yet again in others as high as $60 \%$. The role of viruses in the remaining patients with clinical features of gastroenteritis remains uncertain. Several epidemiological studies have been made in the U.S.A. and Canada (McLean, McNaughton \& Wyllie, 1961; Cramblett \& Siewers, 1965; Yow et al., 1966; Moffet, Shulenberger \& Burkholder, 1968). In some of these ECHO viruses were found more often in infants with diarrhoea than in controls. Similarly, culture of adenoviruses has also been reported both from the U.S.A. and Europe (Kjellen, Zetterberg \& Svedmyr, 1957; Moffet et al., 1968). Some workers, however, consider that adenoviruses and enteroviruses are unlikely to be significant causes of uncomplicated diarrhoeal disease (Bell \& Grist, 1967).

In several childhood series from Western countries no bacterial or viral pathogen has been found in $40-85 \%$ of cases, but in developing countries such as Indonesia this figure may fall to about $10 \%$ (Dewanoto et al., 1968). The cause of the gastroenteritis syndrome in these cases remains quite unexplained.

\section{Salmonella enteritis}

At the Royal Alexandra Hospital for Children $75 \%$ of cases are due to the Salmonella typhimuriam (Dorman, 1969). Infection with Salmonella may be limited to the intestinal tract or it may be bloodborne. When infections with Salmonella (other than Salmonella typhi) are confined to the intestine these should not be treated with antibiotics, as this may in fact prolong the carrier state (Dixon, 1965). However, septicaemia should always be treated with chloramphenicol or ampicillin (Cushing, 1967).

\section{Shigella enteritis}

Although the large bowel is principally affected when there is infection of the gut with this organism, the small bowel is also involved. The commonest species seen at the Royal Alexandra Hospital for Children are Shigella sonnei and Shigella flexner which account for $76 \%$ and $16 \%$ of the Shigella isolates respectively (Dorman, 1969). The value of 
antibiotic therapy in Shigella infections is uncertain and in general this is withheld unless the child remains toxic and feverish after restoration of fluid and electrolyte balance (Cushing, 1967).

\section{Enteropathogenic Escherichia coli infections}

Certain serotypes of the Escherichia coli may cause the syndrome of gastroenteritis in children under the age of 2 years. These serotypes are described under the term enteropathogenic $E$. coli (Neter, 1959). In Sydney, serotypes 0127/B8 and 055/B5 are at present most often seen (Dorman, 1969). Neonatal infection with these organisms is particularly dangerous and can spread rapidly through a nursery. Antibiotic therapy is indicated and neomycin $100 \mathrm{mg}$ per $\mathrm{kg}$ per day orally should be given for 10 days to all affected infants. Susceptible contacts and asymptomatic infants under the age of 1 year should also be treated.

\section{Seasonal incidence}

Gastroenteritis in Sydney is now a predominantly winter disease (Dorman, 1969). This represents a change from the old pattern of summer diarhoea and is similar to experiences elsewhere (Moffet et al., 1968). During this winter peak the bulk of patients are infants and the percentage of bacterial isolations falls as low as $2-5 \%$.

\section{Management of gastroenteritis}

Most children can be managed at home on a dilute feeding adequate in electrolytes such as equal parts of whey and a 1 - in 8 dilution of sweetened condensed milk, with frequent feedings and a total fluid intake greater than $20 \%$ of the child's usual fluid requirements.

For patients with dehydration, restoration of fluid and electrolyte balance is vital and this can only be done by intravenous infusion. Indeed this is the most important aspect of management of this condition. Antibiotics are only secondarily important.

\section{Long-term complications}

Malabsorption of fat and sugar in infants and toddlers (Sunshine \& Kretchmer, 1964; Burke et al., 1965) may follow gastroenteritis for varying intervals, but little is known of the relative incidence and duration of such complications nor their longterm effect on growth and development. Secondary disaccharide intolerance may occur more commonly in some epidemics (Lloyd-Still, 1969), but no association between an aetiological agent and this complication has been observed. Although disaccharide intolerance occurs most often as a complication of gastroenteritis, occasionally transient monosaccharide malabsorption may occur.

\section{Sugar malabsorption}

The observation that disaccharidase activity was localized to the brush border or microvilli of the columnar epithelial cells lining the small intestine (Miller \& Crane, 1961) paved the way for the recognition of deficiencies of such activity and the clinical syndromes produced thereby. However, not only have such deficiencies of disaccharidase activity been described, but also, failure of the next step in sugar absorption, viz. the active transport of monosaccharides, has been observed (Lindquist, Meeuwisse $\&$ Melin, 1962). Both situations produce a malabsorption of sugar with diarrhoea as the principal symptom, whilst the offending sugar or sugars are present in the diet. This diarrhoea is chiefly osmotic due to the effect of the presence of unsplit disaccharide in the small-bowel lumen (Laws \& Neale, 1966; Launiala, 1968). This undigested lactose is fermented by bacteria in the large bowel forming lactic acid (Weijers et al., 1961) and short-chain fatty acids.

\section{Diagnosis}

The stools of children with sugar malabsorption are typically watery and acid when the offending sugar is present in their diet.

Simple screening tests for sugar malabsorption in infants are the estimation of stool $\mathrm{pH}$ and the detection of reducing substances in the stool using Clinitest tablets (Burke et al., 1965). Both these tests are only satisfactory when stools are collected correctly and only the liquid part of the stool should be tested. Collection of the stool on a non-absorptive material, such as plastic, is necessary. If sucrose is the possible offending sugar the stool should be hydrolysed before testing with Clinitest tablets (Burke et al., 1965). The presence of loose watery stools with a pH of 4 or 5 which contain 1 or $2 \%$ reducing substances is diagnostic of sugar malabsorption.

This method of diagnosis is not so reliable in older children and adults (McMichael, Webb \& Dawson, 1965). The development of diarrhoea after an oral load of the offending sugar or the demonstration of an abnormal barium-lactose meal (Laws \& Neale, 1966; Walker-Smith \& Bowdler, 1968) are of more value in diagnosis. A simple sugar tolerance test may be unreliable as the demonstration of a flat tolerance curve does not indicate clinically significant sugar malabsorption unless diarrhoea follows the oral sugar load. Similarly, the demonstration of low disaccharidase activity in a single biopsy from the proximal small-bowel mucosa does not necessarily mean that disaccharide malabsorption of clinical moment is present (Prader \& Auricchio, 1965). The distal gut may act as a functional reserve for diaccharide digestion and absorption. The final proof of a diagnosis of sugar malabsorption causing 
symptoms is the demonstration of a clinical response to the removal of the offending sugar or sugars from the diet.

A number of clinical syndromes have been recognized in which sugar malabsorption occurs.

\section{Primary sucrase-isomaltase deficiency}

This uncommon condition appears to be recessively inherited (Kerry \& Townley, 1965) and is characterized by diarrhoea following the introduction into the infant's diet of sucrose and starch. The small bowel mucosa, on biopsy, is normal (Auricchio et al., 1961).

\section{Congenital alactasia}

This rare primary congenital syndrome was first reported by Holzel, Schwarz \& Sutcliffe (1959). It is characterized by diarrhoea from a few days after birth. In only a few cases has estimation of enzyme activity in a specimen of small intestinal mucosa been performed (Davidson et al., 1964; Lifshitz, 1966; Launiala, Kuitunen \& Visakorpi, 1966). In these lactase activity is not always completely absent, i.e. there is a hypolactasia. It appears to be recessively inherited (Holzel, 1968).

\section{Secondary disaccharidase deficiency}

In paediatric practice in Sydney, malabsorption of sugar is most commonly seen as a complication of gastroenteritis. However, it has also been described as a complication of coeliac disease (Shmerling et al., 1964), giardiasis (Durand \& La Medica, 1964), protein-calorie malnutrition (Bowie, Brinkman \& Hansen, 1965) and following neonatal surgery (Burke \& Anderson, 1966a).

Its presence should be suspected whenever diarrhoea develops, following change in the sugar content of the feedings of an infant recovering from gastroenteritis, or in a child with persistent diarrhoea after gastroenteritis. In those patients who have had enzyme-assay of the intestinal mucosa lactase is the enzyme usually deficient, but sucrase activity may also be depressed. Indeed, some observers suggest that secondary lactose malabsorption is generally accompanied by sucrose malabsorption (Clayton, Arthur \& Francis, 1966).

Once this diagnosis has been made 'lactose-free' milks which contain only insignificant amounts of lactose are prescribed. These include Glucose Nutramigen which contains glucose as its principal sugar, Sobee which contains sucrose as its carbohydrate, Galactomin formula 17 glucose-based and Galactomin formula 19 fructose-based. The 'Galactomin' milks are vitamin-free and vitamin supplementation is essential.

The length of time an infant should remain on such a feed is usually based on clinical response.
Once weight gain is satisfactory, either normal feeds can be recommenced or else a sugar loading test performed and effect on stools etc., observed. Disaccharide intolerance as a complication of gastroenteritis is a transitory phenomenon, but its duration is very variable and may last from a few days to several months.

\section{Genetic aspects of lactose malabsorption}

A genetic aetiology has been suggested for lactose malabsorption of later onset. Indeed, a racial incidence of lactase deficiency has been shown in Bantu Africans (both in Uganda and South Africa) (Cook \& Kajubi, 1966; Jersky \& Kinsley, 1967), Greek Cypriots (McMichael, Webb \& Dawson, 1966), Indians, Chinese, New Guinea natives (Bolin, Crane \& Davis, 1968) and Australian aborigines (Elliott, Maxwell \& Vawser, 1967). This incidence has been explained either on the basis of a genetically determined fall in lactase activity (Cook, 1967) or an acquired defect resulting from the lack of continued substrate challenge in the form of a low level of milk consumption (Bolin et al., 1968). Secondary damage to intestinal mucosa from gastroenteritis or proteincalorie malnutrition would contribute to the severity of such a defect.

In the case of the Australian aboriginal child clinical lactose malabsorption is probably multifactorial in origin. Gastroenteritis is a commonillness amongst aboriginal and part-aboriginal children and further study will be necessary to determine the importance of mucosal damage secondary to this in the genesis of lactase deficiency in these children. The frequency and clinical importance of this lactase deficiency is also uncertain.

Nine aboriginal or part-aboriginal children have had small-bowel biopsies performed at the Royal Alexandra Hospital for Children and all had some degree of villous atrophy histologically. Although all except two had abnormal lactose tolerance tests (blood sugar rise of less than $30 \mathrm{mg} \%$ after an oral load of $2 \cdot 2 \mathrm{~g} / \mathrm{kg}$ lactose) only three had abnormal barium-lactose meals, i.e. evidence that lactose malabsorption of clinical significance was present.

\section{Monosaccharide malabsorption}

A congenital disturbance of the active transport mechanism for the monosaccharides known as glucose-galactose malabsorption has been described by Lindquist et al. (1962). These children only tolerate fructose and whilst having a fructose-containing formula such as Galactomin formula 19 their progress is satisfactory.

Transitory forms of monosaccharide malabsorption have also been described in kwashiorkor (Wharton, 1968) and after neonatal surgery (Burke \& Anderson, 1966a). The mechanism of production 
of such malabsorption is uncertain, but Burke \& Anderson postulated bacterial overgrowth in a stagnant loop as the cause, as they demonstrated bacteria in the duodenal aspirate from these patients. Recently the term 'contaminated-smallbowel syndrome' has been introduced to describe this condition (Gracey, Burke \& Anderson, 1969).

At the Royal Alexandra Hospital for Children infants have also been seen who clinically have had evidence of monosaccharide intolerance after neonatal surgery for intestinal atresia. In addition three children have been seen who transiently could not tolerate glucose-containing feedings after gastroenteritis, but thrived on fructose-containing Galactomin 19.

There has also been a report of infants who were temporarily unable to absorb any monosaccharide including fructose (Burke \& Danks, 1966c). The cause of this transient malabsorption was not established although bowel infection was also postulated as a possible mechanism. Two infants with evidence of malabsorption of all monosaccharides have been seen at the Royal Alexandra Hospital for Children. Both infants developed watery diarrhoea as a sequel to neonatal surgery. One had had a colostomy performed for Hirschsprung's disease and the other had had a bowel resection for ileal atresia. Both were intolerant of glucose and fructose and continued to have acid stools and reducing substances in their stools unless they had a completely sugar-free feeding.

\footnotetext{
Abnormality of small intestinal lymphatics

Dilatation of the small intestinal lymphatics in infancy and childhood has been described by several authors (McKendry, Lindsay \& Gerstein, 1957; Jarnum, 1961). This has usually been called intestinal lymphangiectasia, although histologically it may have an appearance best described as a lymphangioma (Walker-Smith et al., 1969c). Intestinal lymphangiectasia has been described either as a primary abnormality, or as a secondary manifestation of some other disease process (e.g., constrictive pericarditis) (Peterson \& Hastrup, 1963). This abnormality may be accompanied by generalized lymphatic abnormalities outside the alimentary tract including lymphoedema, chylous ascites and hypoplasia or aplasia of the peripheral lymphatic system (Jarnum, 1961; Mistilis \& Skyring, 1966; Poley et al., 1967), but the lymphatic abnormality may be confined to the small bowel and its mesentery. It is usually accompanied by hypoproteinaemic oedema, but not invariably (McKendry et al., 1957). Radio-isotope studies in some of these children have demonstrated that the hypoproteinaemia is due to abnormal protein loss into the gut (protein-losing enteropathy) (Jarnum, 1961).
}

A diet based on medium chain triglycerides (Holt, 1964) has been reported to lead to clinical remission in children who have intestinal lymphangiectasia, but some may be resistant to this therapy (WalkerSmith et al., 1969c).

\section{Parasitic infestations of the small intestine}

Parasitic infestations, as seen in paediatric practice in Sydney, generally occur in aboriginal or partaboriginal children and institutionalized children, because of the comparatively low standards of sanitation in these groups. In most instances such parasitic infestations produce no clinical manifestations, but when they do it is often difficult to determine pathogenicity and the role of a particular parasite in a child's clinical condition because of the presence of other parasites and other disease processes.

Two parasites, Giardia lamblia and Strongyloides stercoralis, may damage the small-bowel mucosa in childhood. Infestation with both may be accompanied by malabsorption. Such malabsorption in parasitosis may be related to structural damage to the small-bowel mucosa, but it has been suggested that intestinal bacteria may play a role (León-Barúa \& Lumbreras-Cruz, 1968).

\section{Giardiasis}

Giardia lamblia, a flagellate protozoon, may infest the proximal small intestine in children and may be found in the glandular crypts of the duodeno-jejunal mucosa. Significant mucosal damage, usually partial villous atrophy, but sometimes subtotal villous atrophy has been demonstrated in infestations with this parasite (Hubble, 1963; Anderson, 1966). Giardiasis may cause the syndrome of acute gastroenteritis, but more often produces chronic diarrhoea which may be accompanied by malabsorption.

The diagnosis is usually made by examination of the stools for cysts or trophozoites, but the duodenal aspirate may contain the protozoon. Barbezat et al. (1967) found Giardia lamblia in the duodenal aspirate of $75 \%$ of fifty-two children with proteincalorie malnutrition whilst the parasite was identified in the stools of only $12 \%$ of these children. However, the mere demonstration of the presence of this parasite in a child does not necessarily indicate that it is of clinical significance. The standard treatment in the past has been mepacrine, but metronidazole (Flagyl) is equally effective (Powell, 1968).

\section{Strongyloidiasis}

Infestation with the nematode Strongyloides stercoralis is found not infrequently in aboriginal and part-aboriginal children in Australia. During the life-cycle of this parasite, the larvae invade the mucosa of the proximal small intestine and there 
develop into adult worms within the wall of the small bowel. However, unlike infestation with Ascaris lumbricoides the adult Strongyloides worms are not usually found in the bowel lumen. The ova are laid in the gut wall and the hatched larvae subsequently migrate into the bowel lumen; with further maturation of the larvae autoinfection further down the small bowel may occur. In addition the larvae may migrate into other organs such as the regional lymph nodes.

Adult and larval invasion of the intestinal mucosa may cause a catarrhal, oedematous or ulcerative enteritis (De Paola et al., 1962). The usual clinical manifestations of such an enteritis are a severe watery diarrhoea producing a clinical syndrome like acute gastroenteritis. Intestinal obstruction as a sequel to an oedematous enteritis has been demonstrated (Walker-Smith et al., 1969d). Strongyloidiasis may also produce malabsorption which is cured by eradication of the parasite (Booth, 1965).

Small-bowel biopsy in children with Strongyloidiasis may demonstrate parasitic invasion of the mucosa as well as partial villous atrophy. The diagnosis is generally made by the demonstration of the larvae of Strongyloides stercoralis in stools or by duodenal aspiration. There is often an eosinophilia in the peripheral blood. Infestation with this parasite may be effectively treated with thiabendazole.

\section{Crohn's disease}

This predominantly adult disease which chiefly affects the terminal ileum is not often seen in childhood. It may occur in older children: Silverman (1966) described fourteen cases aged at diagnosis between 8 and 15 years. They presented as pseudoappendicitis, fever of undetermined origin or growth failure. Only eight had gastrointestinal symptoms on presentation. Four cases of Crohn's disease involving the jejunum which affected children aged between 10 and 12 years at diagnosis have been described by Chrispin \& Tempany (1967), but they had few gastrointestinal symptoms and their dominant clinical features were systemic.

At the Royal Alexandra Hospital for Children only two children in recent years have had the diagnosis of Crohn's disease histologically proven and each had pseudo-appendicitis. The usual way in which this disease is diagnosed is by barium followthrough, but repeated barium studies may be necessary.

\section{Malrotation of the gut}

Children with this abnormality can present acutely with intestinal volvulus, but may present insidiously with intermittent diarrhoea and malabsorption. This condition can often only be diagnosed with certainty at laparotomy and barium studies, although helpful in diagnosis, if normal, do not exclude malrotation. Such a malrotation with chronic volvulus may cause lymphatic blockage with proteinlosing enteropathy (Burke \& Anderson, 1966b) and may also produce all the features of a blind-loop syndrome.

\section{Congenital anomalies of the small intestine}

Atresia of the small bowel (complete occlusion) is more common than stenosis (incomplete occlusion). An alalysis of thirty-five cases of atresia seen at the Royal Alexandra Hospital for Children (Middleton, 1965) revealed that duodenal atresia occurred most often (twenty cases) and there were eleven children with jejunal and four with ileal atresia. In five of these there were multiple atresias. Two-thirds had symptoms in the first $6 \mathrm{hr}$ of life and the entire group with $24 \mathrm{hr}$. These were bilious vomiting, abdominal distension of varying degree and lack of passage of meconium. This condition requires urgent surgical treatment and the type of anastomosis used varies widely.

Their post-operative course is often complicated by infection. In addition, sugar intolerance may occur and there may be evidence of intestinal stasis with a stagnant-loop syndrome as mentioned earlier:

The stagnant-loop syndrome as described in adult patients has steatorrhoea and vitamin $B_{12}$ malabsorption as its principal features. However, reports in the paediatric literature differ as to the chief features of intestinal stasis in children. Bayes \& Hamilton (1969) have described two infants who developed diarrhoea following neonatal surgery for intestinal atresia who were found to have evidence of intestinal stasis with steatorrhoea. They did not describe sugar intolerance in these children. Burke \& Anderson (1966a) described malabsorption of sugar in infants who had had neonatal surgery for atresia and other anomalies and they suggested that this could be related to intestinal stasis and bacterial overgrowth disturbing sugar digestion and absorption.

At the Royal Alexandra Hospital for Children a neonate with duodenal atresia, who had a duodenojejunostomy, developed a watery diarrhoea 12 days after the anastomosis. The stools were acid and contained reducing substances, but no fat globules or fatty acid crystals. The diarrhoea did not settle and weight gain was not satisfactory till Galactomin 19 was introduced into the diet (Fig. 5a). A barium meal revealed a dilated proximal duodenum with stasis of barium (Fig. 5b). The child subsequently died from an intercurrent Pseudomonas septicaemia and at necropsy the anastomosis was patent, but the proximal duodenum dilated. Under the dissecting microscope the mucosa was convoluted in appearance and almost flat (Fig. 5c). Thus, there was evidence in this infant that he had a monosaccharide intolerance 


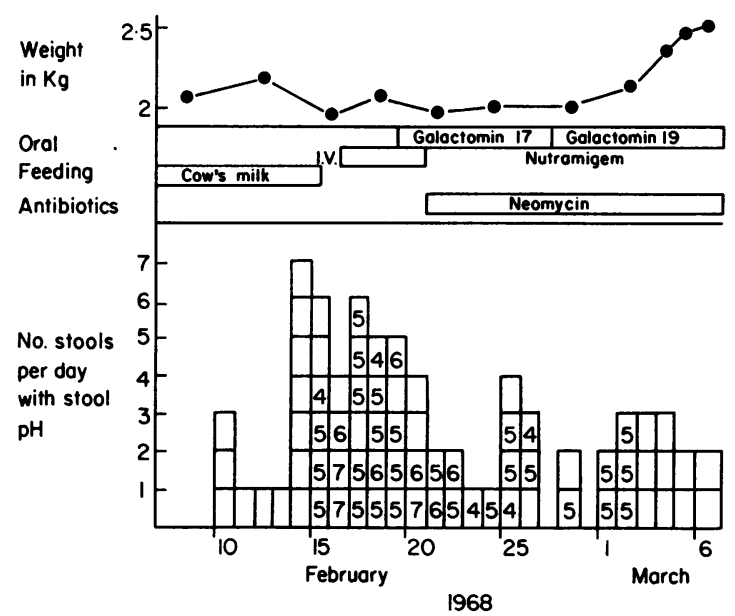

Fig. 5a. Effect of dietary manipulation on stools and weight gain in infant with duodeno-jejunostomy for duodenal atresia.

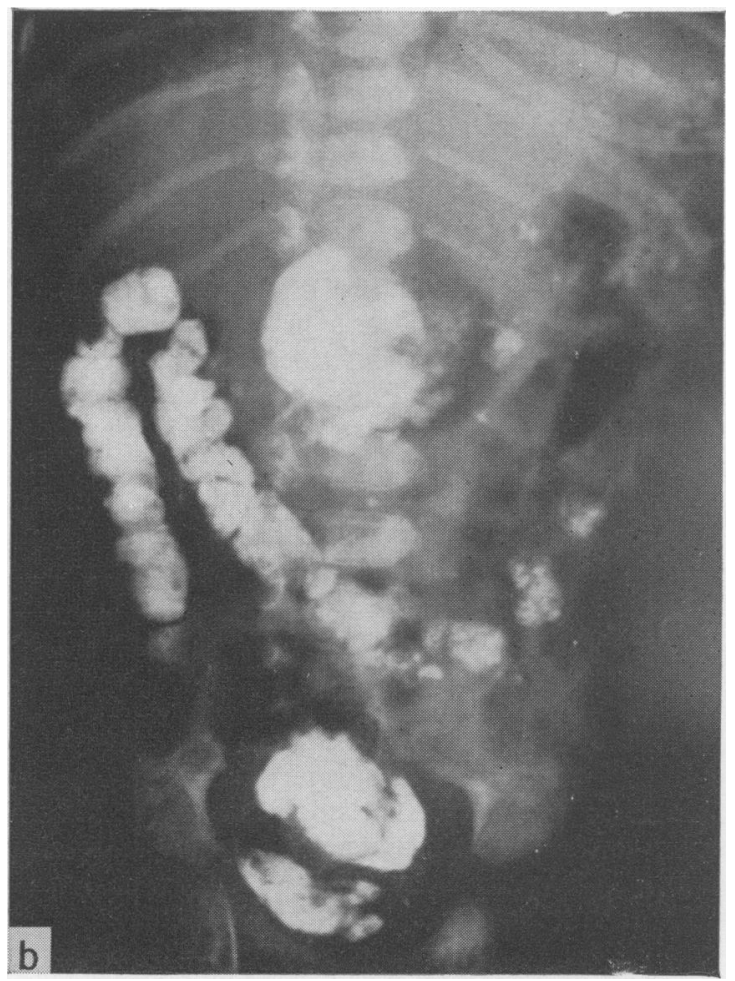

Fig. 5b. X-ray of abdomen $48 \mathrm{hr}$ after a barium meal 3 weeks post-operatively.

and stasis of the contents of his proximal duodenum which was structurally abnormal.

Further work is indicated to study the incidence and mechanisms of fat and sugar malabsorption as

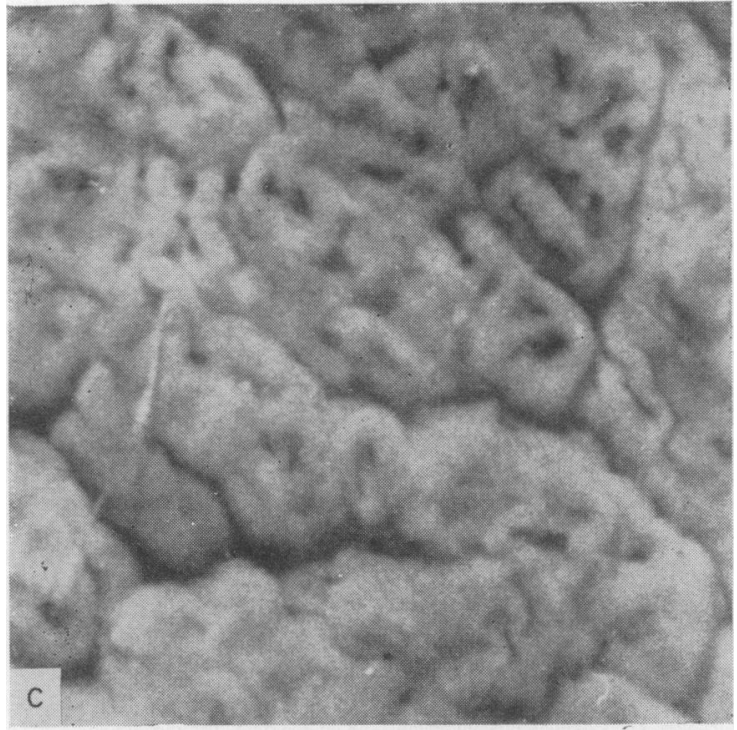

Fig. 5c. Appearance of duodenal mucosa under the dissecting microscope at post-mortem.

well as the state of the intestinal mucosa in such circumstances.

Intestinal stenosis or a congenital intestinal diaphragm both producing intestinal stasis, leading to a stagnant loop syndrome, may present later during childhood. One such case seen at the Royal Alexandra Hospital for Children presented with severe malabsorption with steatorrhoea and a clinical picture very similar to coeliac disease. Laparotomy revealed an ileal stenosis and resection of the stenotic bowel led to a dramatic improvement in the child's general condition and disappearance of malabsorption.

\section{References}

ANDERSON, C.M. (1960) Histological changes in the duodenal mucosa in coeliac disease. Archives of Disease in Childhood, 35, 419.

ANDERSON, C.M. (1966) Intestinal malabsorption in childhood. Archives of Disease in Childhood, 41, 571.

Auricchio, S., Prader, A., Mürset, G. \& WiTt, G. (1961) Saccharoseintoleranz. Durchfall infolge hereditären Mangels an intestinaler Saccharaseaktivität. Helvetica paediatrica acta. 16, 483.

Barbezat, G.O., Bowie, M.D., Kaschula, R.O.C. \& HANSEN, J.D.L. (1967) Studies on the small intestinal mucosa of children with protein-calorie malnutrition. South African Medical Journal, 41, 1031.

BAYES, B.J. \& HAMiLton, J.R. (1969) Blind loop syndrome in children. Malabsorption secondary to intestinal stasis. Archives of Disease in Childhood, 44, 76.

BeLl, E.J. \& GRIST, N. (1967) Viruses in diarrhoeal disease. British Medical Journal, 4, 741.

Bolin, T.D., Crane, G.G. \& Davis, A.E. (1968) Lactose intolerance in various ethnic groups in south-east Asia. Australasian Annals of Medicine, 17, 300. 
Booth, C.C., Stewart, J.S., Holmes, R. \& Brackenbury, W. (1962) Dissecting microscope appearances of intestinal mucosa. Intestinal Biopsy: (Ciba Foundation Study Group No. 14). Churchill, London.

Bоoтн, C.C. (1965) Physiopathology of intestinal malabsorption. Recent Advances in Gastroenterology. Churchill, London.

BooTH, C.C. (1968) Enteropoiesis: Structural and functional relationships of the enterocyte. Postgraduate Medical Journal, 44, 12.

Bowie, M.D., Brinkman, G.L. \& Hansen, J.D.L. (1965) Acquired disaccharide intolerance in malnutrition. Journal of Pediatrics, 66, 1083.

BRonsteIn, H.D., HAEFFNER, I.J. \& Kowlessar, O.D. (1966) Enzymatic digestion of gliadin: The effect of the resultant peptides in adult coeliac disease. Clinica chimica Acta. 14, 141.

Burke, V., Kerry, K.R. \& Anderson, C.M. (1965) The relationship of dietary lactose to refractory diarrhoea in infancy. Australian Paediatric Journal, 1, 147.

Burke, V. \& ANDERSON, C.M. (1966a) Sugar intolerance as a cause of protracted diarrhoea following surgery of the gastrointestinal tract in neonates. Australian Paediatric Journal, 2, 219.

Burke, V. \& Anderson, C.M. (1966b) Chronic volvulus as a cause of hypoproteinaemia, oedema and tetany. Australian Paediatric Journal, 2, 114.

Burke, V. \& Danks, D.M. (1966c) Monosaccharide malabsorption in young infants. Lancet, i, 1177.

Cameron, A.H., Astley, R., Hallowell, M., Rawson, A.B., Miller, C.G., French, J.M. \& Hubble, D.V. (1962) Duodeno-jejunal biopsy in the investigation of children with coeliac disease. Quarterly Journal of Medicine, 31, 125.

Carter, C., Sheldon, W. \& Walker, C. (1959) The inheritance of coeliac disease. Annals of Human Genetics, 23, 266.

Chrispin, A.R. \& Tempany, E. (1967) Crohn's disease of the jejunum in children. Archives of Disease in Childhood, $42,631$.

Clayton, B.E., Arthur, A.B. \& Francis, D.E.M. (1966) Early dietary management of sugar intolerance in infancy. British Medical Journal, 2, 679.

CooK, G.C. \& KaJUBI, S.K. (1966) Tribal incidence of lactase deficiency in Uganda. Lancet, $\mathbf{i}, 725$.

Cook, G.C. (1967) The practical significance of lactase deficiency in childhood. Journal of Tropical Pediatrics, 13, 85.

Cooke, W.T., Fone, D.J., Cox, E.V., Meynell, M.J. \& Gaddie, R. (1963) Adult coeliac disease. Gut, 4, 279.

Cramblett, H.G. \& Siewers, C.M.F. (1965) The etiology of gastroenteritis in infants and children, with emphasis on the occurrence of simultaneous mixed viral-bacterial infections. Pediatrics, 35, 885.

Crosby, W.H. \& Kugler, H.W. (1957) Intraluminal biopsy of the small intestine: The intestinal biopsy capsule. American Journal of Digestive Diseases, 2, 236.

Cushing, A.H. (1967) Diagnosis and treatment: Antibiotic therapy of infectious diarrhoea in children. Journal of Pediatrics, 40, 656.

Danks, D.M., Allan, J. \& Anderson, C.M. (1965) A genetic study of fibrocystic disease of the pancreas. Annals of Human Genetics, 28, 323.

Davidson, M., Sobel, E.H., Kugler, M.M. \& Prader, A. (1964) Intestinal lactase deficiency of presumed congenital origin in two older children. Gastroenterology, 46, 737.

de PaOla, D., Dias, L.B. \& Da Silva, J.R. (1962) Enteritis due to Strongyloides sterionalis. American Journal of Digestive Diseases, 7, 1086.

Dewanoto, O., Alisjahbana, A., Erwinn, S. \& Soegiri (1968) Diarrhea in children between the age of 0-2 years in Bandung. Paediatrica Indonesiana, 8, 45 .
Dexter, D. \& Gowing, N.F.C. (1954) An unusual form of alimentary tract ulceration in infants. Journal of Pathology and Bacteriology, 68, 259.

Dicke, W.K. (1950) Coeliakie. M.D. Thesis, University of Utrecht.

Dixon, J. (1965) Effect of antibiotic treatment on duration of excretion of Salmonella typhimurium by children. British Medical Journal, 2, 1343.

Doolan, P.D., Kyle, L.H., Hess, W. \& Phelps, E. (1951) Gastrocolostomy: Clinical observations and experimental studies. Gastroenterology, 18, 566.

Dorman, D. (1969) Personal communication.

Douglas, A.P. \& BoоTH, C.C. (1968) Jejunal mucosal digestion of gluten peptides in adult coeliac disease. Lancet, ii, 491.

Durand, P. \& La Medica, J.M. (1962) Disaccharide intolerance. Helvetica Paediatrica Acta, 17, 395.

Elliott, R.B., Maxwell, G.M. \& Vawser, N. (1967) Lactose maldigestion in Australian aboriginal children. Medical Journal of Australia, 1, 46.

Frazer, A.C. (1968) Malabsorption Syndromes. William Heineman, London.

GelfaNd, M.D., SPIro, H.M. \& Herskovic, T. (1968) Small intestine glutaminase deficiency in celiac disease. American Journal of Digestive Diseases, 13, 638.

GerRaRD, J.W. \& Lubos, M.C. (1967) The malabsorption syndromes. Pediatric Clinics of North America, 14, 73.

Giles, C., Sangster, G. \& SMith, J. (1949) Epidemic gastroenteritis of infants in Aberdeen during 1947. Archives of Disease in Childhood, 24, 45.

Gracey, M., Burke, V. \& Anderson, C.M. (1969) Association of monosaccharide malabsorption with abnormal small intestinal flora. Lancet, ii, 384.

Hamilton, J.R., LynCh, M.J. \& Reilly, B.J. (1969) Active coeliac disease in childhood. Quarterly Journal of Medicine, 38, 135.

HARRIS, O.D., CoOKe, W.T., Thompson, H. \& W WTERhouse, J.A.H. (1967) Malignancy in adult coeliac disease and idiopathic steatorrhoea. American Journal of Medicine, 42, 899.

Heiner, D.C., Lahey, M.E., Wilson, J.F., Gerrard, J.W., Shwachman, H. \& Khaw, K.T. (1962) Precipitins to antigens of wheat and cow's milk in celiac disease. Pediatrics, 61, 813.

Hobbs, J.R. \& Hepner, G.W (1968) Deficiency of $\gamma \mathrm{M}$ globulin in coeliac disease. Lancet, i, 217.

Hoffman, H.N., Wollaeger, E.E. \& Greenberg, E. (1966) Discordance for nontropical sprue (adult celiac disease) in a monozygotic twin pair. Gastroenterology, 51, 36.

HolT, P.R. (1964) Dietary treatment of protein loss in intestinal lymphangiectasia. The effect of eliminating dietary long chain triglycerides on albumin metabolism in this condition. Pediatrics, 34, 629.

Holzel, A., Schwarz, V. \& Sutcliffe, K.W. (1959) Defective lactose absorption causing malnutrition in infancy. Lancet, i, 1126.

Holzel, A. (1968) Defects of sugar absorption. Proceedings of the Royal Society of Medicine, 61, 1095.

Hooft, C., Devos, E., Kriekemans, J. \& Van Damme, J. (1968) Malabsorption and diabetes mellitus in children. Helvetica paediatrica Acta 5, 478.

Hubble, D. (1963) Diagnosis and management of coeliac disease in childhood. British Medical Journal, 2, 701.

Hutchison, R. (1925) Lectures on Diseases of Children. p. 79. Arnold, London.

IMMONEN, P. (1967) Levels of the serum immunoglobulins $\gamma \mathrm{A}, \gamma \mathrm{G}$ and $\gamma \mathrm{M}$ in the malabsorption syndrome in children. Annales Paediatric Fennae, 13, 115.

JARNUM, S. (1961) Protein-losing Gastroenteropathy. Blackwell Scientific Publications, Oxford. 
JERSKY, J. \& KINSLEY, R.H. (1967) Lactase deficiency in the South African Bantu. South African Medical Journal, 41, 1194.

Joske, R.A. \& Benson, J.A. (1958) ABO blood groups and nontropical sprue. Gastroenterology, 34, 408.

KenRICK, K.G. \& WALKeR-Smith, J.A. (1970) Immunoglobulins and dietary protein antibodies in childhood coeliac disease. (In press).

KERRY, K.R. \& TOWNLEY, R.R.W. (1965) Genetic aspects of sucrase-isomaltase deficiency. Australian Paediatric Journal, 1, 223.

Kuellen, L., Zetterberg, B. \& Svedmyr, A. (1957) An epidemic among Swedish children caused by Adenovirus type 3. Acta paediatrica Scandinavica, 46, 561.

launiala, K., Kuitunen, P. \& Visakorpi, J.K. (1966) Disaccharidases and histology of duodenal mucosa in congenital lactose malabsorption. Acta paediatrica (Uppsala), 55, 257.

LAUNIALA, K. (1968) The mechanism of diarrhoea in congenital disaccharide malabsorption. Acta paediatrica Scandinavica, 57, 425.

Laws, J.W. \& Neale, G. (1966) Radiological diagnosis of disaccharidase deficiency. Lancet, ii, 139.

LEón-BARÚA, R. \& Lumbreras-Cruz, H. (1968) The possible role of intestinal bacterial flora in the genesis of diarrhea and malabsorption associated with parasitosis. Gastroenterology, 55, 559.

Lifshitz, F. (1966) Congenital lactase deficiency. Journal of Pediatrics, 69, 229.

Lindquist, B., Meeuwisse, G. \& Melin, K. (1962) Glucosegalactose malabsorption. Lancet, ii, 666.

LLOYD-STILL, J. (1969) Gastroenteritis with secondary disaccharide intolerance. An outbreak in a premature unit. Acta paediatrica Scandinavica, 58, 147.

MCConNELL, R.B. (1966) The genetics of gastrointestinal disorders. Oxford Monographs on Medical Genetics. p. 112 Oxford University Press, London

MacDonald, W.C., Dobbins, W.O. \& Rubin, C.E. (1965) Studies of the familial nature of celiac sprue using biopsy of the small intestine. New England Journal of Medicine, 272, 448

MCKendRY, J.B.J., Lindsay, W.K. \& Gerstein, M.C. (1957) Congenital defects of the lymphatics in infancy. Pediatrics, 19, 21

McLean, D.M., McNaughton, G.A. \& Wyllie, J.C. (1961) Infantile gastroenteritis: Further viral investigations. Canadian Medical Association Journal, 85, 496.

McMaHON, R.A. (1966) Massive resection of intestine in infancy. Australian and New Zealand Journal of Surgery, 35, 202.

McMichael, H.B., Webb, J. \& Dawson, A.M. (1965) Lactase deficiency in adults: A cause of "functional" diarrhoea. Lancet, ii, 717.

McMichael, H.B., WebB, J. \& Dawson, A.M. (1966) Jejunal disaccharidases and some observations on the cause of lactase deficiency. British Medical Journal, 2, 1037.

MCNeISH, A.S. (1968a) Diagnosis of coeliac disease in retrospect. Archives of Disease in Childhood, 43, 362.

MCNeISH, A. \& SWEET, E.M. (1968b) Lactose intolerance in childhood coeliac disease: Assessment of its incidence and importance. Archives of Disease in Childhood, 43, 433.

McNicholl, B. \& EgaN, B. (1968) Jejunal biopsy in celiac disease. Clinical Pediatrics, 7, 544.

Middleton, A.W. (1965) Personal communication.

Miller, D. \& Crane, R.K. (1961) The digestive function of the epithelium of the small intenstine. I. An intracellular locus of disaccharide and sugar phosphate ester hydrolysis. Biochimica et Biophysica Acta, 52, 281.

Mistilis, S.P. \& SKYRING, A.P. (1966) Intestinal lymphangiectasia: Therapeutic effect of lymph venous anastomosis. Journal of the American Medical Association, 40, 634.
Moffet, H.L., Shulenberger, H.K. \& Burkholder, E.R. (1968) Epidemiology and etiology of severe infantile diarrhoea. Journal of Pediatrics, 72, 1.

Mortimer, P.E., Stewart, J.S., Norman, A.P. \& Booth, C.C. (1968) Follow-up study of coeliac disease. British Medical Journal, 2, 7.

Müller, M., Walker-Smith, J.A., Shmerling, D.H., Curtius, H.-CH. \& Prader, A. (1969) Lactulose: A gasliquid chromatography method of determination and evaluation of its use to assess intestinal mucosal damage. Clinica Chimica Acta, 24, 45.

Neter, E. (1959) Enteritis due to enteropathogenic Escherichia coli. Present-day status and unsolved problems. Journal of Pediatrics, 55, 223.

Petersen, V.P. \& Hastrup, J. (1963) Protein losing enteropathy in constrictive pericarditis. Acta Medica Scandinavica, 173, 401.

Poley, J.R., Lesch, P., Hitzig, W.H. \& Prader, A. (1967) Chylöser ascites untersuchungen über den eiweissstoffwechsel und über den einfluss des nahrungsfetts auf die ascitesproduktion. Helvetica paediatrica Acta, 22, 81 .

Powell, S.J. (1968) Metronidazole: An anti-infective agent of growing importance. Medicine Today, 2, 44.

Prader, A. \& Auricchio, S. (1965) Defects of intestinal disaccharide absorption. Annual Review of Medicine, 16, 345.

Prader, A., Shmerling, D.H. \& Hadorn, B. (1966) Disaccharides and coeliac disease. Lancet, i, 435.

Pringle, E.M., Young, W.F., Mortimer, P.E., Haworth, E.M. \& Newton, R.C.F. (1968) Coeliac syndrome. Proceedings of the Royal Society of Medicine, 61, 775.

Rubin, C.E., Brandborg, L.L., Phelps, P.C. \& Taylor, H.D. (1960a) Studies of celiac disease. I. The apparent identical and specific nature of the duodenal and proximal jejunal lesion in celiac disease and idiopathic sprue. Gastroenterology, 38, 28.

Rubin, C.E., Brandborg, L.L., Flick, A.L., Parmentier, C., Phelps, P.C. \& Van Niel, S. (1960b) The effect of wheat instillation into the proximal ileum of patients with idiopathic sprue. Journal of Clinical Investigation, 39, 1023.

SaKUla, J. \& SHINER, M. (1957) Coeliac disease with atrophy of the small intestine mucosa. Lancet, ii, 876.

Sheldon, W. \& Tempany, E. (1966) Small intestine peroral biopsy in coeliac children. Gut, 7,481 .

ShINeR, M. (1960) Coeliac disease: Histopathological findings in the small intestinal mucosa studied by a peroral biopsy technique. Gut, 1, 48.

Shmerling, D.H., Auricchio, S., Rubino, A., Hadorn, B. \& Prader, A. (1964) Der sekundäre mangel an intestinaler disaccharidaseaktivität bei der cöliakie quantitative bestimmung der enzymaktivität und klinische beurteilung. Helvetica paediatrica Acta, 19, 507.

Shmerling, D.H. (1965) Die cöliakie: Eine übersicht. Internist (Berlin), 6, 46.

ShmerLing, D.H. (1968a) An analysis of controlled relapses in gluten-induced coeliac disease. Proceedings of the European Society for Pedriatric Gastroenterology. Paris.

Shmerling, D.H., Prader, A. \& ZachmanN, M. (1968b) The effect of dietary treatment on growth in coeliac disease. Calorie Deficiencies and Protein Deficiencies-Proceedings of a Colloquium. p. 159. Churchill, London.

SilvermaN, F.N. (1966) Regional enteritis in children. Australian Paediatric Journal, 2, 207.

Stanfield, J.P., Hutt, M.S.R. \& TunNicliffe, R. (1965) Intestinal biopsy in kwashiorkor. Lancet, ii, 519.

Stewart, J.S., Pollock, D.J., Hoffbrand, A.V., Mollin, D.L. \& Bоотн, C.C. (1967) A study of proximal and distal intestinal structure and absorptive function in idiopathic steatorrhoea. Quarterly Journal of Medicine, 36, 425.

Sunshine, P. \& KRETChmer, N. (1964) Studies of small intestine during development. III. Infantile diarrhoea 
associated with intolerance to disaccharides. Pediatrics, 34, 38.

Swanson, V.L. \& Thomassen, R.W. (1965) Pathology of the jejunal mucosa in tropical sprue. American Journal of Pathology, 46, 511.

Taylor, K.B., Thomson, D.L., Truelove, S.C. \& Wright, R. (1961) An immunological study of coeliac disease and idiopathic steatorrhoea. British Medical Journal, 2, 1727.

VISAKORPI, J.K. \& IMMONEN, P. (1967) Intolerance to cow's milk and wheat gluten in the primary malabsorption syndrome in infancy. Acta paediatrica Scandinavica, 56, 49.

WALKer-Smith, J.A. \& Wyndham, N. (1967a) Total loss of mid-gut. Medical Journal of Australia, i, 857.

WALKeR-Smith, J.A. (1967b) Dissecting microscope appearance of small bowel mucosa in children. Archives of Disease in Childhood, 42, 626.

WALKeR-Smith, J.A. \& BowdLeR, J.D. (1968) The role of radiology in the diagnosis of lactose intolerance in children. Gut, 10, 78.

WALKER-Smith, J.A. (1969a) Small bowel morphology in childhood. Medical Journal of Australia, 1, 382.
Walker-Smith, J.A. \& Grigor, W. (1969b) Coeliac disease in a diabetic child. Lancet, $\mathbf{i}, 1021$.

Walker-Smith, J.A., Reye, R.D.K., Soutter, G.B. \& KENRICK, K. (1969c) Small intestinal lymphangioma. Archives of Disease in Childhood, 44, 527.

Walker-Smith, J.A., McMillan, B., Middleton, A.W., RoBertson, S. \& HopCroft, A. (1969d) Strongyloidiasis. causing small bowel obstruction in an aboriginal infant. Medical Journal of Australia, 2, 1263.

WeiJers, H.A. \& VAN DE KAMER, J.H. (1960) Celiac disease and wheat sensitivity. Pediatrics, 25, 127.

Weijers, H.A., VAN De Kamer, J.H., Dicke, W.K. \& IJSSELING, J. (1961) Diarrhoea caused by deficiency of sugar-splitting enzymes. Acta paediatrica (Uppsala), 50, 55.

Wharton, B.A. (1968) Difficulties in the initial treatment of kwashiorkor. Calorie Deficiencies and Protein Deficiencies -Proceedings of a Colloquium. p. 147. Churchill, London,

Yow, M.D., Melnick, J.L., Phillips, C.A., Lee, L.H. South, M.A. \& BlattNer, R.J. (1966) An etiologic investigation of infantile diarrhea in Houston during 1962 and 1963. American Journal of Epidemiology, 83, 255. 